\title{
La relación entre la Internacional Comunista y América Latina: episodios del revolucionario suizo Alfred Stirner ${ }^{1}$
}

\author{
Victor Jeifets y Lazar Jeifets \\ Universidad Estatal de San Petersburgo \\ jeifets@gmail.com - ilaranspb@hotmail.com
}

La apertura de los archivos de la extinta Comintern (Internacional Comunista o III Internacional) desde hace dos décadas presenta para los investigadores muchas nuevas perspectivas para estudios municiosos de los partidos de izquierda, así como para el análisis del papel desempeñado por varios emisarios de la Comintern en diferentes países.

Un asunto importante para los investigadores -como siempre- es el enfoque metodológico para usar durante tales estudios. Según los autores del presente texto, el marco de análisis tradicionalista gramsciano, que pone mayor énfasis en la integración de la historia del partido en la historia de la sociedad (Gramsci, 1972-1980), es poco aplicable para rescatar la historia de gran parte de los partidos izquierdistas latinoamericanos. La propuesta analítica de Gramsci no toma en cuenta que en la mayoría de los países no europeos el nacimiento de movimientos de izquierda y comunistas no se debe a la evolución previa del movimiento obrero. Además, durante varios años, la lógica de desarrollo del partido comunista y de la Comintern estipulaba una adaptación de las actividades de la izquierda a los estándares universales impuestos por la III Internacional. Debido a estas particularidades de la evolución de los movimientos de izquierda en América Latina, la investigación de la vida de los actores políticos que implementaban la "línea de Moscú" -o a veces se oponian a ella- tiene un valor especial para el análisis. El estudio de la vida de estos actores puede implicar una cierta personalización de los hechos históricos a costa de prestar una menor atención a la lógica de desarrollo de los grupos locales de izquierda. Sin embargo, es prerrequisito para comprender mejor el movimiento de la izquierda. El

1. Este artículo fue realizado en el marco del proyecto de investigación apoyado por la Fundación Estatal Rusa de Humanidades (RGNF), n 1601-00138, "La Revolución Rusa, la Comintern y América Latina".

(Archivos, año VI, $\mathrm{n}^{\circ} 11$, septiembre de 2017, pp. 57-77) 
reconocido militante del Partido Comunista de México, de la Comintern y de la Internacional de Juventudes Comunistas, Edgar Woog, a lo largo de dos décadas fue uno de estos actores clave del campo político de la izquierda en el aparato central de la III Internacional y en el desarrollo de algunos grupos de izquierda de diferentes países.

Cualquier miembro de la Comintern tenía una sola patria, una sola Meca comunista, o sea la Rusia soviética, y consideraba como su santo deber revolucionario defender esta "patria del proletariado mundial" de los ataques de parte del capital internacional y nacional, luchando a favor de una revolución mundial fuera de los límites de los Estados burgueses nacionales. Los estatutos de la Comintern establecian las obligaciones de los afiliados de ingresar en las secciones nacionales de la III Internacional al mudarse de un país a otro y esta regla no toleraba excepciones, siendo prerrequisito para los militantes de base y los emisarios de la Comintern. Edgar Woog, objeto de estudio del presente artículo, tuvo que actuar en cuatro secciones nacionales de la III Internacional durante el periodo de sus actividades revolucionarias. Siendo funcionario internacional de la Comintern y experto en los asuntos latinoamericanos, realizaba actividades cotidianas de interacción con los militantes de izquierda en varios países del subcontinente. Sin embargo, nunca fue un ejemplo típico de la llamada "mano de hierro de Moscú" (una imagen formada en la historiografia del movimiento comunista desde hace décadas: Alba, 1964; Alexander, 1957; Goldenberg, 1971), que supuestamente definía no solamente líneas directrices sino incluso los pormenores del comportamiento de tal o cual sección nacional de la III Internacional. La escala amplia de las actividades realizadas por Woog permiten considerarlo como un funcionario "modelo" para definir hasta qué punto la Comintern imponía en determinados periodos sus directivas en el movimiento internacional comunista.

Repetidas veces la biografia de Woog había sido investigada en diversos aspectos (Huber, 1994; Studer, 1994; Stettler, 1980); sin embargo, cada vez los episodios latinoamericanos de su actividad seguian siendo una laguna historiográfica (Ortiz, 2011: 272-283). No obstante, durante diez años (o sea casi todo el período "romántico" de la historia de la III Internacional), estuvo en el epicentro de la formación de los partidos comunistas en el hemisferio occidental, cuando la política latinoamericana de la Comintern estaba sujeta a cambios permanentes.

\section{Edgar Woog y los origenes de la Internacional de Juventudes Comunistas en América Latina}

El futuro funcionario cominternista nació el 24 de abril de 1898 en Basilea, Suiza, y su padre era dueño de un pequeño taller textil. El ne- 
gocio familiar tenía dificultades económicas y, a la edad de 16 años, el joven tuvo que aprender varios oficios: era ayudante en una empresa que vendía trigo, luego trabajaba como jornalero y ayudaba a su padre en el taller. Al mismo tiempo, estudiaba en una escuela secundaria, después de la cual ingresó en una escuela comercial y, además, aprendió el oficio de bibliotecario. Desde temprano inició sus actividades revolucionarias, siendo militante de la Unión Estudiantil Internacional (desde 1916) y de la Sozialistische Jugend Schweiz. Trabajaba en el periódico de la SJZ, Freie Jugend (Juventud Libre), y en 1918 llegó a ser miembro del Comité Central de la organización. Al siguiente año se afilió al Sozialistischen Partei der Schweiz. ${ }^{2}$

Durante la Primera Guerra Mundial, Suiza se convirtió en un punto clave del movimiento revolucionario internacional, siendo la sede de dos conferencias importantes, en Zimmerwald y en Kienthal, convocadas por los socialdemócratas que estaban en contra de este conflicto imperialista, y en las que se discutió la idea de formar una nueva Internacional que reuniera a los marxistas revolucionarios y antimilitaristas. Los jóvenes socialdemócratas suizos percibian las nuevas ideas con buen ánimo y estaban dispuestos a realizarlas en la vida práctica de inmediato.

Precisamente en ese momento, Woog viaja por primera vez a México cumpliendo una encomienda de su padre, que lo había enviado a ayudar al hermano mayor, que estaba estableciendo un negocio en las tierras aztecas. Sin embargo, el joven socialista nunca quiso limitarse a los asuntos familiares. Según escribió años más tarde en su autobiografia para el Departamento del Personal de la Comintern, fue a México "con ganas de ver el mundo y teniendo plena certeza de que alli debía haber un movimiento obrero". ${ }^{3}$ Llegó a México en el otoño de 1919, y trabajó en una imprenta y en una farmacia intentando al mismo tiempo aprender el idioma español para comunicarse mejor con sus correligionarios locales. Precisamente en esos meses el Partido Socialista fue transformado en el Partido Comunista Mexicano, y el Bureau Latinoamericano de la III Internacional fue fundado en la ciudad de México (Martínez Verdugo, 1985; Taibo II, 1986; Spenser, 1998). En diciembre de 1919 el suizo se encontró con el secretrio del PCM y del Bureau, José Allen, presentándose como delegado de la Internacional de Juventudes Comunistas. Efectivamente, había avisado a sus compañeros del movimiento juvenil sobre su viaje al hemisferio occidental, y el Secretariado de Basilea de la IJC fundado a la sazón decidió aprovechar esa posibilidad. Obtuvo un representante en un país latinoamericano sin gastar ni un centavo.

2. Carpeta personal de E. Woog, Archivo Estatal Ruso de Historia Política y Social (RGASPI, por sus siglas en ruso), fondo 495, inventario 65a, expediente 8536, f. 4 (34).

3. Autobiografia de E. Woog, RGASPI, fondo 17, inv. 98, exp. 6811, f. 9. 
De ahí en adelante, Woog usará todo su tiempo libre en los trabajos partidarios. El negociante Woog desaparece por décadas, y en vez de él llega al mundo "Alfred Stirner", el funcionario comunista internacional. Y solo en las cartas personales se recordaba a un "Eggi".

La tarea principal de Stirner, en enero de 1920, fue la fundación, junto con los mexicanos F. Torres y José Valadés, de una organización juvenil estrechamente vinculada al PCM. ${ }^{4}$ Era un conglomerado de comunistas y anarco-sindicalistas que originalmente se titulaba Unión de la Juventud Igualitaria. Sin embargo, tras romper con la UJI, Stirner y Valadés formaron en octubre de 1920 la Federación de Jóvenes Comunistas, que también tuvo una vida visiblemente efimera y estuvo varias veces a punto de desbandarse, a causa de contradicciones agudas entre los comunistas y los anarquistas. ${ }^{5}$

Al tomar en cuenta la cercanía geográfica entre México y los Estados Unidos, el Ejecutivo de la IJC consideró el movimiento juvenil comunista local una "pieza clave", y prometió a la FJC todo tipo de apoyo (lo que nunca cumplió en la práctica). A Stirner le encargaron dirigir un subsecretariado de la IJC para América del Centro y del Sur (de hecho, él mismo era el unico miembro de este subsecretariado), colaborando políticamente con el Bureau Latinoamericano de la III Internacional. ${ }^{6}$ Los dirigentes berlineses de la IJC propusieron a su delegado que establezca amplios contactos con las organizaciones juveniles en Sudamérica, pero todos los intentos del subsecretariado de organizar una actividad "continental" fracasaron por completo, sobre todo por falta de comunicación postal estable con los demás países de América. Según Stirner, ni en Uruguay, ni en Argentina, ni en Perú, ni en Chile había organizaciones juveniles "bien eficientes"' (lo que era erróneo, por lo menos en el caso de la Argentina: la FJC de este país no se comparaba con sus homólogos europeos por su influencia (Gilbert, 2009), pero la juventud mexicana elogiada por el suizo ni siquiera llegaba a los niveles de organización rioplatense). Además, el entusiasmo del militante suizo no podía cubrir todas las áreas de trabajo y, mientras tanto, la IJC no disponía de recursos financieros para enviar a otros emisarios para apoyarle. En México, la actividad de Stirner era semilegal (los extranjeros tenían prohibido participar en la vida política del país), lo cual complicaba, naturalmente, sus tareas.

4. Kurella (1930: 87) y carpeta personal de E. Woog, f. 4 (34).

5. "The Communist Youth of Mexico", RGASPI, fondo 495, inv. 18, exp. 65, fs. 142-143.

6. "Stirner zu Ziegler", 6 de noviembre de 1920, RGASPI, fondo 533, inv. 4, exp. 3, fs. 40-40 vuelta.

7. "Der Brief aus Berlin zu Stirner", 3 de septiembre de 1920, RGASPI, fondo 533, inv. 3, exp. 14, fs. 26-27. 
El suizo demostraba muchas ilusiones respecto de la posibilidad de una próxima revolución proletaria y rechazaba las posibilidades de trabajo fructífero entre los estudiantes, ya que "había muy poca gente consciente" en las universidades; propuso, a su vez, enfocarse en las actividades de propaganda entre los obreros. Obviamente influido por el anarco-sindicalismo mexicano, hacía notar el carácter "explosivo" del movimiento obrero, el cual, según Stirner, tendría todas los chances de apoderarse de la capital del país en el momento favorable. Anunció a sus dirigentes que los comunistas ya estaban formando grupos clandestinos para dar forma a los preparativos revolucionarios. ${ }^{8} \mathrm{Al}$ parecer, eran meras fantasías del suizo. Sin embargo, logró otra cosa: el 15 de enero de 1921, tras una nueva reorganización de locales juveniles, aparece la Federación de Juventudes Comunistas de México, que en pocos meses aumentó el número de sus militantes hasta una cifra de un centenar de personas, lo que contrastaba visiblemente con la cantidad miserable que tenían ambos partidos comunistas en México, que ni siquiera juntos alzancaban este nivel.

Por cierto, Stirner demostraba un enfoque más realista sobre las perspecitivas del fortalecimiento posterior de la FJCM y explicaba al comité ejecutivo que era imposible desplegar un trabajo de gran escala por falta de conexión con las masas. Pero incluso bajo estas circunstancias los jóvenes comunistas asumieron sobre sus hombros la carga principal de la organización partidaria en México. Eran Stirner, Valadés y otros miembros de la FJC los que realizaban el trabajo cotidiano de organización, en lugar del PCM, que estaba "medio dormido". La FJCM logró contribuir visiblemente a la fundación de la Federación Comunista del Proletariado Mexicano, para entregar luego al Partido Comunista los hilos de su dirección.

La otra contribución del suizo al movimiento de la izquierda local tampoco se puede subestimar: pudo revitalizar los enlaces entre los comunistas mexicanos con sus correligionarios en Europa y la Comintern, ya que estos contactos casi se desvanecieron tras la salida del país del emisario de la III Internacional en el hemisferio occidental, Mijail Borodin. El PCM solicitó a Stirner que busque algun compatriota suyo para representar a México en una conferencia comunista en Europa, y el joven enviado del CE de la IJC no tardó en proponer a Jules Humbert-Droz para el desempeño de tales funciones, informándole al mismo tiempo sobre la existencia del Bureau Latinoamericano de la III Internacional y sobre un eventual congreso continental comunista, supuestamente

8. Kurella (1930: 88); "Stirner zu Ziegler", 3 de abril de 1922, RGASPI, fondo 533, inv. 4, exp. 15, f. 15; "Brief aus Mexiko", 7 de junio de 1922, RGASPI, fondo 44; "Die Briefe zu Stirner aus Berlin", octubre-diciembre de 1920, RGASPI, inv. 3, exp. 14, fs. $29-31$ y 33 . 
preparado por este bureau. Reconociendo que al movimiento obrero le faltaba una orientación ideológica clara y que no disponía de los recursos necesarios para las actividades cotidianas de organización, Stirner al mismo tiempo estaba absolutamente seguro de que México se enfrentaría a una revolución socialista dentro de muy poco tiempo. Según sus estimaciones algo exageradas, en este caso los mexicanos serian capaces de resistir la ofensiva de Washington y el eventual bloqueo de parte de los estadounidenses; sin embargo, solicitaba con urgencia que se explique el asunto al CC del Partido Comunista Ruso, para que Moscú preste más atención al país latinoamericano referido. ${ }^{9}$

Mientras ningun nuevo delegado de la Comintern fue designado para México tras la salida de Borodin, al suizo le tocó desempeñar también las funciones de emisario de la III Internacional. Lo primero que tuvo que averiguar fue la esencia del conflicto entre los dos partidos comunistas recién fundados: el Partido Comunista Mexicano y el Partido Comunista de México (sobre este conflicto, véase Carr, 1997; Jeifets, 2006). Strirner tomó partido de manera decidida por el primer grupo, lo cual no debe sorprender pues tenía relaciones amistosas con José Allen y José Valadés, ambos involucrados en las actividades del PCM. En septiembre de 1920 tildó al fundador del PCdM, Linn A. E. Gale, de "menchevique" y "representante de la sociedad de traidores de la causa proletaria", ajena a la Comintern. En nombre del PCM, pidió al CE de la IJC que contribuya a "desenmascarar" a Gale y le niegue el derecho de llamarse comunista. En octubre del mismo año, el emisario de la IJC escribió una carta a sus superiores solicitando ayuda para establecer contacto entre México y el Bureau de Ayuda Técnica a Rusia Soviética en los Estados Unidos, encabezado por el ingeniero Ludwig Martens (considerado por las autoridades estadounidenses la sucursal de la III Internacional y perseguido por policía). ${ }^{10}$ No se sabe nada sobre la realización de esta idea de ampliar enlaces comunistas entre México y los Estados Unidos, pero al parecer nunca se pudo hacer algo al respecto.

A su vez, Stirner fue encargado por el CE de la IJC de concurrir al Congreso de la Internacional Juvenil Comunista en Moscú y organizar el envío de otro delegado mexicano. Sin embargo, la FJCM no contaba con dinero para el viaje de dos personas y, por otra parte, no logró designar otro representante en el breve lapso temporal que disponia para ello. A final de cuentas, el suizo resultó ser el único delegado de los jóvenes comunistas mexicanos y asistió al congreso con voz y voto bajo el seudónimo "Til"; además estuvo en las reunions del III Congreso de la

9. "Stirner aus Mexiko zu Humbert-Droz", 27 de mayo de 1922, RGASPI, fondo 533, inv. 4, exp. 3, fs. 10-11 y 22.

10. "Stirner zu Eggi", 25 de septiembre de 1922, ibídem, fs. 35-38. 
Comintern que tuvo lugar casi al mismo tiempo, en $1921 .{ }^{11} \mathrm{El}$ delegado del PCM en el congreso del comunismo mundial fue Manuel Díaz Ramírez, amigo cercano de Stirner. Los dos mantuvieron contactos durante casi una década, sin importar la distancia geográfica que les separara.

Al regresar a México, el suizo se sumó a las actividades del Bureau Panamericano de la Comintern, dirigido por el viejo militante japonés Sen Katayama desde marzo de 1921. Stirner, entre otras cosas, participaba en la edición de los periódicos La Plebe y El Obrero Comunista, y junto con Valadés se ocupó de reorganizar las células y los locales de la FJCM para darles un carácter mas combativo y hacerlos más eficientes. Los jóvenes comunistas cooperaban activamente con el Bureau Mexicano de la Internacional Sindical Roja, encabezado por uno de los fundadores del PCM, Charles Phillips (Frank Seaman) que había regresado a México tras participar en el II Congreso de la Comintern en 1920, ya siendo emisario del Partido Comunista mundial (Shipman, 1993). Los dos representantes internacionales de los cuerpos superiores del comunismo, Stirner por la IJC y Phillips por la IC, a veces se enfrentaban seriamente. Sus conflictos se debian, sobre todo, a la postura poco flexible del comunista estadounidense hacia el movimiento juvenil y sus exigencies de desligarse por completo de los elementos que no eran "suficientemente comunistas". Al mismo tiempo, Stirner modificó sustancialmente sus posturas previas y ya no esperaba una revolución inmediata, lo que le llevó a la conclusion de que México difería mucho de Europa y por eso la FJCM no podia "darse el lujo" de autoaislarse de los partidarios potenciales para dejárselos a los anarquistas. ${ }^{12}$ Esta evolución hacia las actitudes más moderadas marcó varios años de sus actividades posteriores en México y en el estado mayor de la III Internacional.

\section{E1 latinoamericanista principal de la Comintern}

Ya en el año 1922, Stirner dejó de desempeñar las funciones de delegado de la IJC en América Latina. Sin embargo, los contactos establecidos durante ese corto lapso temporal determinaron su actividad posterior dentro de la izquierda latinoamericana y su importante papel entre los funcionarios de alto rango de la Comintern. En vísperas del IV Congreso de la III Internacional el suizo fue designado como persona responsable

11. Listas de delegados al III Congreso de la Comintern y las credenciales de los delegados en RGASPI, fondo 490, inv. 1, exp. 201, fs. 1a, 5, 19, 23; también, L. y V. Jeifets (2015).

12. "The Communist Youth of Mexico", ob. cit.; "José a Eggi", 22 de abril de 1921, RGASPI, fondo 495, inv. 108, exp. 14, f. 7 vuelta; "Der Brief aus Mexiko für L.", 9 de febrero de 1922, RGASPI, fondo 533, inv. 4, exp. 15, f. 7. 
del Departamento de Estadística e Información del CEIC, con la tarea de editar el semanario informativo en varios idiomas, reflejando las noticias de la III Internacional, y recopilar los datos estadísticos sobre economía y movimiento obrero internacional (Adibekov et al., 1997). ${ }^{13} \mathrm{El}$ Departamento funcionaba en interacción con los asesores sobre diferentes regiones (uno de los cuales, encargado de los asuntos de Portugal, España, México y Sudamérica, era el mismo Stirner, designado por el Bureau de Organización el 10 de noviembre de 1923). Durante dos años, desde el IV hasta el V Congreso de la Comintern (1922 y 1924) preparó 33 informes sobre condiciones en la región para el Ejecutivo de la III Internacional y su Presidium. ${ }^{14}$ Cabe anotar que no era un trabajo de un funcionario irrelevante. Entre los asesores del CEIC en aquel entonces figuraban muchos personajes clave de la izquierda comunista internacional, entre ellos Antonio Gramsci, Nikolai Bujarin, Karl Radek, Grigory Zinoviev, Wasil Kolarow, Otto Kuusinen y otros.

En el IV Congreso de la Comintern, el suizo fue elegido miembro del CEIC por Sudamérica, entrando de esa manera en las filas de alta jerarquía del partido comunista mundial. Sin embargo, en el V Congreso (en el cual Stirner representaba como delegado al CEIC y desempeñaba funciones de miembro del secretariado y de la comisión del programa del congreso) fue resuelto que en adelante el subcontinente estuviera representado en el CEIC por el PC de la Argentina en vez del PC Mexicano. Stirner dejó de ser miembro del CEIC, pero inmediatamente fue incluido en la Comisión Internacional de Control (CIC) como delegado mexicano y elegido secretario del CIC, todo esto sin dejar de trabajar en el Departamento de Información y Estadística. Después del congreso fue varias veces incluido como experto en varias comisiones de la Comintern creadas para investigar las cuestiones de España, Holanda, Alemania (el caso de H. Brandler y A. Talheimer, los dos dirigentes comunistas alemanes acusados de desviación) y México. La nueva reorganización del aparato del CEIC llevó a Stirner al Secretariado del CEIC para los asuntos de España, Portugal, Argentina, México, Brasil, Chile, Paraguay y Cuba.

Todos esos años el suizo mantuvo sus relaciones cercanas con los dirigentes del PCM y dos veces fue llamado por éstos desde Moscú para participar en la liquidación de serias crisis dentro del Partido Comunista. Desde la capital soviética, el suizo realizaba una vasta correspondencia oficial y personal con los comunistas de varios grupos y partidos de

13. G.M.Adibekov, E.N.Shakhnazarova, K.K.Shirinia. Organizatsionnaya struktura Kominterna. 1919-1943. M., Rosspen, 1997, p. 75-76.

14. Dva goda borby i raboty. Obzor deyatelnosti Ispolkoma i sektsii Kommunisticheskogo Internatsionala za period s IV po V congress, Moscú: Krasnaya, noviembre de 1924, p. 113 y 124; Adibekov et al. (1997: 89). 
izquierda y estaba al tanto del desarrollo de muchos partidos comunistas. Además, era uno de los pocos funcionarios cominternistas que dominaban el idioma español y el único experto de la III Interrnacional en los asuntos latinoamericanos. No hay que extrañarse, por eso, de que casi siempre estuviera en el centro de las discusiones acerca de los asuntos de la vida de la izquierda latinoamericana y participara en la elaboración de documentos que luego eran objeto de análisis por los altos mandos de la Comintern y base para sus resoluciones políticas. El Archivo Estatal Ruso de Historia Social y Política resguarda muchas cartas escritas por Stirner o dirigidas a él que permiten investigar los pormenores de su trabajo dentro del aparato cominternista y analizar las particularidades de las relaciones entre Moscú y varios grupos y partidos políticos en América Latina.

\section{En busca de nuevos lideres}

La dirigencia de la Comintern en la primera parte de la década del 20 entendía de una manera clara y perfecta el "trauma congénito" del comunismo latinoamericano: una carencia de dirigentes capaces de hablar con amplios sectores de la sociedad, de desarrollar nuevos conceptos que permitieran fortalecer los enlaces de la III Internacional con el subcontinente.

Uno de los primeros candidatos a convertirse en dirigente de "nuevo tipo" fue el líder estudiantil peruano Víctor Raúl Haya de la Torre, que estaba luchando en contra del autoritarismo del presidente Augusto Leguía (1908-1912 y 1919-1930). El fundador de varias Universidades Populares resultó un personaje interesante para el intelectual y político mexicano José Vasconcelos, quien pudo convencer al presidente Álvaro Obregón de la importancia de financiar el viaje de Haya a México (Pakkasvirta, 1997).

El PCM, a su vez, apostó plenamente en Haya de la Torre, con la seguridad de que el líder estudiantil peruano "hizo más para sus ideas quizás que lo que podían hacer sus escasos periódicos publicados en castellano". Esto coincidía plenamente con los conceptos del mismo Haya de la Torre, que queria "irse a Rusia para defenderla a conciencia". Bertram D. Wolfe -el delegado mexicano al V Congreso de la Cominterninstó al Partido Obrero (Comunista) de Estados Unidos de "entrar en el juego", considerando que "la repercusión entre los estudiantes de Argentina, Cuba, Bolivia y Panamá" sería un resultado inmediato de este peregrinaje. ${ }^{15}$ Para aquel entonces, Víctor Raúl ya había ingresado

15. "Carta de Luis", antes del 25 de mayo de 1924, RGASPI, fondo 515, inv. 1, exp. 311 , f. 24. 
al PCM y en mayo de 1924 asistió a su congreso, ${ }^{16}$ llamando a establecer un "gobierno obrero y campesino". Los propósitos de su trabajo partidario eran muy claros: "la formación de los partidos comunistas en el Perú y Panamá".

La estancia de Haya de la Torre en la URSS fue abundante en eventos: asistió al V Congreso Mundial de la Comintern y al III Congreso de la Internacional Sindical Roja, participó en los debates durante el IV Congreso de la Internacional de las Juventudes Comunistas. Preparó un informe sobre la influencia del imperialismo estadounidense en Latinoamérica y estudió minuciosamente la organización de los rabfacks (facultades obreras), para compararla con la experiencia de las universidades populares en Perú y Cuba (Jeifets y Jeifets, 2013). El resultado mas importante de su viaje fue establecer contactos informales con los dirigentes de varias estructuras "cominternianas" que mantuvo durante algunos años. En ese momento fue muy leal al estado mayor de la revolución mundial. ${ }^{17}$

La Comintern recomendó a los PC de Europa Occidental brindarle apoyo, siendo Víctor Raúl el dirigente del movimiento revolucionario estudiantil y progresista de América Latina. Sin embargo, los comunistas no estaban muy apurados en cumplir las indicaciones de Moscú y el "colaborador peruano del partido comunista mundial" tuvo que quejarse en su carta al suizo: "EEuropa proletaria se rie del imperialismo en nuestra América y nos mandan al carajo!"18

Fue en Europa donde Haya de la Torre elaboró un plan de fundación de un nuevo partido politico. En su carta enviada a Stirner manifestó que se trataba de formar un gran partido de obreros y campesinos de Perú: "El programa máximo y mínimo del Partido será el de los P. comunistas pero no usará la palabra para evitar de echarse encima la ofensiva mundial contra el comunismo que no podría soportarse en América por el grado de debilidad de las fuerzas obreras". ${ }^{19}$ No dudaba de que el futuro partido en dos meses tomaría el poder en Perú para desplegar posteriormente la agitación por todos los rincones de América, "para realizar la Federación Latinoamericana sobre la base de supresión de la

16. Acta Constitutiva del PCM con fines electorales, 22 de mayo de 1924, Centro de Estudios del Movimiento Obrero y Socialista (CEMOS), México, Colección PCM, caja 2, folio 5 .

17. Stirner a Haya de la Torre, [1924], RGASPI, fondo 495, inv. 118, exp. 2, f. 15; [Woog] "al querido HDLT", Moscú, 27 de octubre de 1924, ibídem, f. 1.

18. [¿Woog?] a Jacques Doriot, Moscú, 27 de octubre de 1924, ibídem, f. 12; [Woog] a HDLT, Moscú, 27 de octubre de 1924, 1; Haya de la Torre a Stirner, Ginebra, 23 de noviembre de 1924, ibídem, f. 20 vuelta.

19. Haya de la Torre a Stirner, no antes del 9 de diciembre de 1924, ibídem, 1. 28-30. 
explotación capitalista, nacionalización de la industria y modernización del sistema social del comunismo incaico para la producción agrícola" ${ }^{20}$ Efectivamente, se trataba de organizar una revolución continental con Perú como su epicentro. El peruano solicitó a Stirner averiguar la opinion del CEIC acerca del programa propuesto. Usando la retórica cominterniana, Haya de la Torre hablaba con frecuencia sobre "nuestro trabajo" y confirmaba su deseo de coordinar sus esfuerzos con los del CEIC. ${ }^{21}$

El experto cominternista consideraba la situación en Perú como propicia para el movimiento revolucionario; sin embargo, estaba seguro de que las concepciones de Haya eran "demasiado abstractas". Y el mayor obstáculo para realizar las ideas de Víctor Raúl, según el suizo, era precisamente este futuro partido "organizado directamente para asumir el poder", en el cual su jefe seria "casi el único que tiene una concepción más o menos marxista del movimiento revolucionario". La conclusión de Woog era muy desilusionante para Haya de la Torre:

Un partido, sin experiencia, sin una dirección formada por hombres que tienen los mismos conceptos, que tienen la misma línea de conducta en los diferentes problemas que se presenten, que tienen una experiencia bastante para darles seguridad en sus paros, sin un tal partido, no se toma el poder para aplastar a la burguesía -a la burguesía, no solo a los terratenientes- $[\ldots]$ sin un partido de hierro, sin un grupo de compañeros perfectamente educados a base de la experiencia misma y la del movimiento revolucionario ruso y del período de reconstrucción que en Rusia se hace desde la revolución de octubre, no podrán mantenerse en el poder ni dos meses. ${ }^{22}$

Woog no se cansaba de explicar al futuro jefe de la revolución continental los limites de las capacidades de la Comintern:

Debes comprender que la IC debe de concentrar todas sus fuerzas para empujar la revolución adelante en Francia, Alemania e Italia. [...] Existe tanta materia para conflictos internacionales como nunca, entre otro también el nuevo peligro de nuevas intervenciones y guerras en contra de la Rusia Soviética. Todo esto hace que la IC no dé toda aquella atención a nuestros países como nosotros creemos que debe de darse. ${ }^{23}$

20. Ibídem.

21. Ibídem, f. 31 .

22. [Woog] a Haya de la Torre, Moscú, 12 de enero de 1925, ibídem, f. 34.

23. Ibídem, f. 33. 
Stirner estaba intentando organizar un nuevo viaje de Haya de la Torre a Moscú para que asista con informe al pleno ampliado del CEIC. Sin embargo, el asunto se atoró por las cuestiones financieras: la Comintern sugirió a Haya de la Torre buscar el dinero por su propia cuenta. La maquinaria burocrática del CEIC funcionaba lentamente y no logró resolver a tiempo la cuestión, que no le hubiera costado tanto en términos financieros pero podría haber sido muy fructífera desde la perspectiva de la revolución mundial (como la veía la Comintern en aquel entonces).

En vez de Moscú, Haya de la Torre fue a Londres para luego regresar a México y fundar la Alianza Popular Revolucionaria Americana, cuyo programa estaba casi copiado de varias ideas ya expuestas en las cartas del peruano a Woog. Al mismo tiempo, el APRA fue definido como "un movimiento autónomo latinoamericano sin ninguna intervención o influencia extranjera" (Istoriya Peru..., 2000: 306; Skalov, 1934: 105, 223). Tras el Congreso Antimperialista en Bruselas en 1927 se produjo la ruptura definitiva entre Moscú y el líder aprista.

Mientras tanto, Stirner también se fue a México, pero esto ya no tuvo nada que ver con relaciones entre la Comintern y Haya de la Torre. El Secretariado del CEIC envió al suizo a su "segunda patria" cumpliendo la solicitud del PCM para que éste participara en la resolución de una grave crisis dentro del Partido Comunista acerca de la táctica en el asunto campesino. El ex secretario general del PCM, Manuel Díaz Ramírez, insistía en mudar la sede del CC al estado de Veracruz, epicentro del potente movimiento agrarista. Ese cambio definiría un nuevo modelo del comunismo mexicano, dándole más eficiencia a nivel regional. Los planes no se realizaron por la fuerte oposición de nuevos dirigentes del PCM: Bertram D. Wolfe y Rafael Carrillo Azpeitia, quienes abogaron por que el Comité Central se quedara en la ciudad de México, argumentando que el PC de Estados Unidos sólo accedería a la creación de una oficina panamericana si se llevara a cabo en la capital. ${ }^{24} \mathrm{Al}$ querer recibir cien pájaros volando (un deseo de devolver el centro continental del movimiento comunista latinoamericano a su país) los comunistas mexicanos estaban dispuestos a sacrificar los pocos pájaros que ya tenian en sus manos (las relaciones amistosas con los dirigentes campesinos procomunistas).

Este dilema se vio agravado por los conflictos personales, que en última instancia llevaron a una ruptura entre el PCM y su local en Veracruz, encabezado por Úrsulo Galván y Manuel Almanza, quienes apoyaron a Manuel Díaz Ramírez. Según el representante de los comunistas estadounidenses en México, Charles Phillips ("Manuel Gómez"), 
la relación entre el partido y los agraristas veracruzanos pendía de "un hilo muy delgado". ${ }^{25}$

En agosto de 1925, la dirección del partido había retirado a Díaz Ramírez de su cargo de jefe de la célula del PCM en Xalapa, expulsándole al mismo tiempo. ${ }^{26}$ Pero, incluso cumpliendo formalmente los trámites de retirada de Díaz Ramírez, los xalapeños le reemplazaron con Almanza, respaldando efectivamente al líder caído en desgracia. ${ }^{27}$ Se negaron absolutamente a obedecer la prohibición de discutir sus diferencias con otras organizaciones, y aclararon que no confiaban en Carrillo. Obviamente, había diferentes aproximaciones al problema de las relaciones con el gobierno. Si el Comité Central del PCM insistió en la protesta obligatoria de Galván, como diputado del congreso local, contra las acciones del gobierno estatal en la represión de la huelga en la Huasteca, la célula de Xalapa francamente no entendió por qué "debe sacrificar el armamento de los campesinos de esta Liga, y por ende su propia integridad, en bien de una protesta, que no dará ningún resultado práctico". ${ }^{28}$

Desde el Comité Central se hicieron acusaciones de oportunismo y una insubordinación a la Comintern. ${ }^{29}$ En respuesta, impulsados por Díaz Ramírez, los jalapeños pusieron en duda la eficacia del Comité Central: "En Tampico, Veracruz, Michoacán, Estado de México [...] en todas partes donde hay alguna influencia de nuestro pequeño e incipiente P.[artido]; ha sido conseguida por nuestros viejos miembros, los que han seguido más o menos nuestra política. ¿Ellos, qué tienen en el Distrito Federal siquiera? Nada. Absolutamente nada". ${ }^{30}$ Galván sentía cada vez más irritación con respecto a la posición de Carrillo, y Díaz Ramírez advirtió a Moscú acerca de sus temores de que el líder de la Liga ("la única organización sobre la que tenemos una influencia decisiva") "mandara al diablo" al Comité Central. ${ }^{31}$ Esto no podría ocasionar más que graves consecuencias para el partido. Galván, al ser una figura de importancia nacional, fue también una de las figuras clave en la política de Veracruz, y los comunistas no tendrían con quién sustituirlo.

Hasta finales de 1925 la Liga incluso tuvo previsto el nombramiento

25. Carta de M. Gómez, 4 de septiembre de 1926, RGASPI, fondo 515, inv. 1, exp. 717, f. 8.

26. RGASPI, fondo 495, inv. 108, exp. 49, f. 33.

27. Ibídem, f. 40.

28. Ibídem, f. 41.

29. Ibídem, f. 46.

30. Ibídem, f. 73 .

31. M. Díaz Ramírez a Stirner, 27 de octubre de 1925, RGASPI, fondo 495, inv. 108, exp. 49 , f. 76 . 
de los comunistas Díaz Ramírez y Almanza como candidatos al congreso federal (en nombre del Partido Campesino "Tierra y Libertad"). En caso de ser elegidos, la posición del PCM en sus relaciones con el movimiento agrario sería aún más ambigua. Percibida la brecha de la alianza agrario-comunista, sólo pudo ser suavizada por la intervención de Stirner, el representante de la Comintern, quien a través de un telegrama ordenó de inmediato "detener la lucha faccional [entre] Rafael [Carrillo] y Manuel [Díaz Ramírez]". ${ }^{32}$

Stirner tomó la decisión de remitir el problema al mando superior de la III Internacional. Confirmando la actitud del Comité Central del PCM de que el trabajo de los comunistas entre los campesinos "no siempre mantenía una línea correcta", el "protector" superior de los comunistas mexicanos resumió claramente a los líderes de la Internacional Comunista el otro lado del problema: los disidentes del Comité Central estaban todos metidos en el movimiento campesino de Veracruz, por lo que las expulsiones se marginarian al PCM de la mayoría de las organizaciones en el campo. Stirner dijo con franqueza que el partido "había cortado la rama que lo sostenía", reforzando la influencia del ala anticomunista del movimiento agrarista. ${ }^{33}$ Ante la imposibilidad de que ambos competidores (Carrillo y Díaz Ramírez) fueran a Moscú por falta de recursos, la Comintern tuvo que enviar de nuevo a México a Stirner para intervenir en la disputa en el VI Congreso del PCM.

Durante el congreso, el suizo se enfrascó en un duro conflicto con el embajador soviético Stanislav Pestkovsky, quien apoyó inequivocamente a Wolfe y a Carrillo, y dijo incluso que "dimitiría como embajador" si ocurría la "rehabilitación" de Ramírez; el embajador exigió que los hilos de dirección del PCM fuesen concentrados en sus manos. ${ }^{34}$ Stirner fue calificado por el diplomático como un "abogado de políticos sinvergüenzas". ${ }^{35}$ La actititud de Stirner fue visiblemente más sopesada y balanceada: "El Partido agradecería cualquier buen consejo que reci-

\section{Ibídem, exp. 45, f. 12.}

33. Ibídem, f. 14. También dijo lo mismo Charles Phillips ("Manuel Gómez"), uno de los fundadores estadounidenses del PCM, que conocía bien la situación: "El intento de excluir a Ramírez fue una típica estupidez. El Comité Central habló sólo de los errores oportunistas de Ramírez, pero ni siquiera prestó atención al hecho de lo que su exclusión podría crear... Díaz Ramírez no sólo debe permanecer en el partido [...], sino ingresar [de nuevo] al Comité Central", ibídem, f. 515, inv. 1, exp. 717, p. 9. Ver también Jeifets y Reynoso Jaime (2014: 15-40).

34. Informe de Andréi al CEIC, 11 de Agosto de 1925, RGASPI, fondo 495, inv. 19, exp. 17 , f. 80 .

35. Informe del representante de la Comintern en México "Andréi" sobre la situación en el país, 15 de septiembre de 1925, RGASPI, fondo 495. inv. 19, exp. 179, f. 31. Sobre las actividades de S. Pestkovsky en México, véase Jeifets y Jeifets (2001). 
biera desde la embajada" (citado en Jeifets y Jeifets, 1999). Al mismo tiempo insistía en que Moscú preste más atención a su representación diplomática en México, siendo ésta la única en todo el hemisferio ${ }^{36} \mathrm{y}$ un punto de atracción política para la izquierda y los antimperialistas no solamente de México sino de varios otros países latinoamericanos.

Stirner se indignó con el aventurerismo bruto y simple de algunos miembros del Comité Central, quienes afirmaban "estar listos" sin los "30.000 miembros de la unión de Veracruz". La discusión fue de lo más abrupta, pero en última instancia la única autoridad provenía de la sede de la Comintern, en la que Stirner tenía preponderancia. En las resoluciones del partido desapareció la calificación simplista del "gobierno laborista" como "un lacayo del imperialismo norteamericano". Finalmente, el Congreso no sólo confirmó la inviolabilidad de la línea del PCM en cuanto a la estrecha alianza con los campesinos, sino que aprobó la tarea de formar en México la Liga Nacional Campesina.

Aproximadamente en estos mismos meses Stirner se encontró en el centro de la crisis de las relaciones entre Moscú y los comunistas venezolanos, aglutinados en aquel momento dentro del Partido Revolucionario Venezolano (PRV), formado en el exilio como una estructura opositora a la dictadura de Juan Vicente Gómez y dispuesto a organizar la lucha armada en contra del dictador. Este plan recibió cierto apoyo de parte del gobierno mexicano (que iba a prestar a los venezolanos antigomecistas armas y dinero).

La mayor parte de los opositores a la dictadura gomecista no estaría complacida con los ideales de una revolución mundial bajo la tutela de la Comintern, por eso los comunistas desde el inicio formaron dentro del PRV un "Grupo Continental Secreto", pensando aprovechar la situación tras la expedición armada a territorio venezolano, para asegurar "el triunfo del comunismo en América". Creían posible tomar el poder en alguno de los países latinoamericanos para formar la base de lucha en otros territorios. ${ }^{37}$ Los delegados de la Comintern en México (Stanislav Pestkovsky, Alfred Stirner y Mijail Grollman ("Oswald") estaban enterados de aquellos planes y los apoyaban. Según ellos, existía una posibilidad de convertir la oposición activa en el exilio venezolano en una base para un potente movimiento antiimperialista. ${ }^{38}$

36. "Bericht A. Stirner. Über die Führung der KP M durch den Gen. Andres", RGASPI, fondo 495, inv. 108, exp. 61, f. 82.

37. Grupo Continental Revolucionario, Salvador de la Plaza, Secretario General, México, 1926; RGASPI, fondo 495, inv. 107, exp. 3, f. 35.

38. The Polpred's Diary. N/d. El Archivo de la Política Exterior de la Federación Rusa (AVPRF, por sus siglas en ruso), Departamento mexicano, fondo 0110, inv. 6, exp. 1, carpeta 101, f. 73; Carta del representante de la Comintern en México A. Stirner al 
En el verano de 1926 el Grupo Continental Revolucionario envió al venezolano comunista Gustavo Machado a Moscú para establecer "relaciones amplias y hermanas" entre el gobierno de la URSS y el "gobierno que esté formado en Venezuela tras el triunfo de la Revolución" y para discutir los pormenores de una acción armada. ${ }^{39}$

Sin embargo, según recordaba después Machado, el CEIC percibió todos los proyectos de expediciones como una actividad sin apoyo en las bases sociales internas. Los comunistas que militaban en el PRV recibieron la orden de ingresar al país y formar un partido revolucionario proletario entre los sectores disconformes de la clase obrera y campesina.${ }^{40} \mathrm{El}$ enviado extraordinario del "Gobierno Revolucionario" de Venezuela quedó muy desilusionado por la actitud oscurantista de las instituciones soviéticas y de la Comintern, pero no logró convencerlas.

Stirner, que estaba en ese momento en México y se comunicaba casi diariamente con los miembros del exilio revolucionario venezolano, no compartía la postura tomada por sus superiores. Tras el fracaso de la misión de Machado, prometió al dirigente del PRV Carlos de León que informaria a la Comintern sobre las necesidades de los revolucionarios venezolanos, pero al mismo tiempo le recomendó emprender su propio viaje a Moscú. El suizo estaba absolutamente seguro de que "los compañeros venezolanos estaban mucho mejor organizados que la gente que estaba dirigiendo el movimiento liberal en Nicaragua y que tenian muchas más perspectivas para resistir a una intervención americana". ${ }^{41}$ Su opinión no logró ningún cambio, a pesar del prestigio de Stirner en el aparato de la III Internacional. Los dirigentes de la Comintern insistian en la justeza de su criterio y negaban el apoyo al PRV considerando irrealizable el plan de organizar una expedición armada antigomecista con los recursos mexicanos y soviéticos. En esas condiciones, Stirner ya no pudo hacer nada para apoyar a sus amigos venezolanos.

encargado del Secretariado Latino J. Humbert-Droz, 27 de mayo de 1927, RGASPI, fondo 495, inv. 19, exp. 181, fs. 92-100.

39. Grupo Continental Revolucionario, Credencial, Salvador de la Plaza, Secretario General, México, 23 de junio de 1926, RGASPI, fondo 495, inv. 107, exp. 3, f. 16; Autobiografia de G. Machado (1952) y carpeta personal de G. Machado, RGASPI, fondo 495, inv. 200, exp. 16, parte 2, fs. 161-162; Salvador de la Plaza al Camarada Alfredo Stirner, México, 23 de junio de 1926, RGASPI, fondo 495, inv. 107, exp. 3, f. 15.

40. G. Machado al Comité Ejecutivo de la Internacional Comunista, RGASPI, fondo 495, inv. 107, exp. 3, f. 59.

41. Carta del representante de la Comintern en México A. Stirner al encargado del Secretariado Latino J. Humbert-Droz, 27 de mayo de 1927. 


\section{Stirner, el PCM y la ruptura con el movimiento campesino}

En 1928, el suizo asumió el puesto de dirigente del Secretariado de Europa Occidental en Berlín, que estaba a cargo de la coordinación de actividades de los principales partidos comunistas del Viejo Mundo. Sin embargo, al poco tiempo los altos mandos de la Comintern decidieron responder positivamente a la solicitud hecha por la delegación del PCM al VI congreso que tuvo lugar ese mismo año (por cierto, Stirner era también parte formal de aquella delegación, aunque sin voto) y enviar al suizo a México para ayudar al PCM durante una nueva crisis interna política que estaba reinando en el país. Y esta vez la actitud del emisario de Moscú hacia el movimiento campesino resultó ser mucho más dura y rígida que en 1926.

Sin embargo, las condiciones politicas no eran las mismas. Durante el motín reaccionario militar de marzo de 1929 los militantes de la Liga Nacional Campesina apoyaron al gobierno y propusieron al PCM que renunciara a la recién iniciada campaña electoral del Bloque Obrero y Campesino, para que las autoridades no tengan que luchar en dos frentes. El PCM, en cambio, criticaba duramente al presidente interino Emilio Portes Gil por su "pasividad" y llamaba a los obreros y campesinos a "organizar nuestras propias fuerzas" para combatir a la reacción. Al reconocer la inevitabilidad de la lucha en contra del motín escobarista, los comunistas esperaban convertir su supresión en una insurrección armada y tomar el poder en varios estados. ${ }^{42}$

Stirner sin vacilaciones apoyó la postura del CC del PCM, considerando que la idea propuesta por el dirigente de la LNC Úrsulo Galván era una maniobra y el inicio de un juego propio en la situación cambiante. No obstante, el intento de los dirigentes campesinos procomunistas en el estado de Durango de conservar las armas que les había entregado el gobierno para la lucha en contra de la sublevación castrense terminó mal. El gobierno reaccionó inesperadamente de manera cruel: dos dirigentes campesinos (entre ellos el miembro del CC del PCM y tesorero de la LNC, José Guadalupe Rodríguez) fueron fusilados. La ejecución arbitraria marcó una línea roja en la paciencia de los comunistas. En esos dias Stirner escribe a Moscú:

El caos imperante en el país se mantendrá a pesar de la derrota del motín antigubernamental, mientras la situación económica va empeorándose casa día [...] hay que realizar todo

42. Informe para el Presidium del CEIC "La situación actual en México", 18 de mayo de 1929, RGASPI, fondo 495, inv. 108, exp. 100, f. 58. 
el trabajo de organización y agitación teniendo en cuenta que dentro de poco tiempo [...] tendremos que guiar a las masas encaminando hacia un movimiento armado a nuestro favor. ${ }^{43}$

Galván rechazó rotundamente radicalizar su postura, culpando al mismo tiempo a los comunistas por los eventos sangrientos en Durango; en unas semanas fue expulsado del PCM. ${ }^{44}$ La evolución drástica de la linea comunista hacia los campesinos en México y hacia el gobierno no fue motivada solamente por Moscú, que ya estaba abogando por la politica de "clase contra clase". En el país posrevolucionario la situación inestable y la costumbre de formar contingentes armados locales eran factores que contribuian a los planes de una lucha armada. Y Stirner no tanto imponía una nueva línea como se sumaba a los procesos internos dentro de la dirigencia del PCM.

Los delegados de la Comintern no consideraban la ruptura con la LNC como algo grave. Según otro emisario de la III Internacional, Mijail Grollman ("Oswald"), "el cadaver de [J.G.] Rodríguez estaba dividiendo al Partido y Galván”. Stirner se solidarizó con él, al declarar que el PCM estaba tomando "un camino correcto". Insistía que en el caso de que hubiera "elecciones sin fraude [...] habríamos ganado una mayoría absoluta". ${ }^{45}$

La realidad era otra. La inmensa parte de la LNC siguió a Galván y abandonó a los comunistas; en las elecciones los campesinos votaron a favor del candidato oficialista o se abstuvieron, lo que se convirtió en uno de los factores de la marginalización del PCM. Según la triste apreciación hecha por el secretario general del PCM Rafael Carrillo, "Galván se fue con todo el movimiento campesino, y nos quedamos en la calle" (Melgar Bao, 1992: 57).

\section{Conclusión}

La historia de la conexión latinoamericana de Stirner-Woog, que había durado más de diez años, llegó a su fin en 1930, cuando el suizo fue incluido en la delegación del CEIC enviada para trabajar con el PC de España como instructor para reorganizar el partido. Tras ser detenido en 1931 y deportado a México, no se detuvo en América Latina, sino

43. Edgar a Manuel, 2 de abril de 1929, RGASPI, f. 3.

44. PCM a Ú. Galván, 16 de mayo de 1929, RGASPI, fondo 495, op. 108, exp. 105, f. 8; R. Carrillo a Güero [Woog], 15 de julio de 1929, ibídem, exp. 104, f. 27; Borrador del telegrama al PC de México elaborado por el Lender-Secretariado del CEIC, ibídem, exp. 100 , f. 60.

45. Informe del CC del PCM al CEIC, 3 de enero de 1930, RGASPI, exp. 132, fs. 7-8. 
que regresó de inmediato al aparato moscovita del Ejecutivo de la Comintern: trabajaba en el Lender-Secretariado Romano e daba cursos en la Escuela Leninista Internacional. En 1935, por fin, su experiencia de organizador fue requerida por la III Internacional en la patria de Woog. Desde ese momento desempeñó un papel importante en el Kommunistische Partei der Schweiz, siendo primero su secretario de organización y luego delegado del KPS al VII congreso de la Comintern en 1935. Al estallar la guerra civil en España, se fue otra vez a la peninsula Ibérica, pero el Comité Central del KPS lo llamó de regreso a Suiza para que se encargue de reclutar a los voluntarios de las Brigadas Internacionales. En 1940 el PKS fue proscripto y Woog trabajó en la clandestinidad, lo que le costó dos encarcelamientos. Fue uno de los inicadores de la fusion de los comunistas con los socialistas de izquierda dentro de un partido legal, el Partei der Arbeit der Schweiz, en 1944. Toda su vida posterior fue en vínculo con el PAS, donde ocupaba puestos del miembro del CC, vicepresidente y secretario del CC. Desde 1949 hasta 1968 fue secretario general del CC del PAS, y en el último tramo de su vida desempeñaba el cargo de presidente de la Comisión Central de Control del PAS.

Sin embargo, América Latina no abandonó por completo la vida del suizo. Mantenía relaciones con varios militantes antiguos de la izquierda latinoamericana y, ya jubilado, compartió sus recuerdos sobre el revolucionario cubano Julio Antonio Mella en el periódico Revolución.

El ejemplo del trabajo del comunista suizo Edgar Woog como uno de los dirigentes e ideólogos del comunismo latinoamericano demuestra que la actividad de la Comintern nunca fue una dogma inamovible. El estado mayor de la revolución mundial estaba lleno de gente viva que disponía sus propias percepciones sobre el movimiento y que tenian perspectivas diferentes sobre el carácter y la esencia de la revolución continental. Sus puntos de vista no siempre coincidian con los de los altos dirigentes de la III Internacional. El papel de esos funcionarios internacionales para la izquierda latinoamericana no puede ser subestimada. Gracias a Edgar Woog cobró fuerza la línea de colaboración con los sectores no marxistas de la izquierda, lo que creaba nuevas perspectivas de crecimiento para varios partidos comunistas. Sin embargo, los puntos de vista del cominternista suizo (así como de otros funcionarios de la III Internacional) estaban sujeto a cambios, sobre todo durante el proceso de la burocratización estalinista que se inició en 1928-1929. Siendo soldado disciplinado del Partido Comunista mundial, Edgar Woog estaba dispuesto a imponer la nueva línea a los sectores de la izquierda latinoamericana, aunque eso significara renunciar a sus conceptos previos. 


\section{Bibliografia}

Alba, V. (1964), Historia del movimiento obrero en América Latina. México: Limusa Wiley.

Alexander, R.J. (1957), Communism in Latin America, New Brunswick-New Jersey: Rutgers University Press.

Carr, B. (1997), La izquierda Mexicana a través del siglo XX, México: Era.

Gilbert, Isidoro (2009), La Fede, Buenos Aires: Sudamericana, 2009.

Goldenberg, B. (1971), Kommunismus in Lateinamerika, Stuttgart-BerlinColonia-Mainz, Verlag W. Kohlhammer.

Gramsci, A. (1972-1980), Notas sobre Maquiavelo, sobre la politica y sobre el Estado moderno, Madrid-Buenos Aires: Nueva Visión.

Huber, P. (1994), Stalins Schatten in die Schweiz, Zurich: Chronos.

Istoriya Peru s drevneishih vremen do kontza XX veka (2000), Moscú: Nauka.

Jeifets, V. (2006), La Comintern y la evolución de la izquierda mexicana [en ruso], San Petersburgo: Nauka.

Jeifets, V. y Jeifets, L. (2015), América Latina en la Internacional Comunista, 1919-1943. Diccionario biográfico, Santiago de Chile: Ariadna.

- (2013), "Haya de la Torre, la Comintern y el Perú, acercamientos y desencuentros", Pacarina del Sur, $\mathrm{n}^{\circ}$ 16, julio-septiembre. Disponible en www.pacarinadelsur.com/home/huellas-y-voces/764-haya-de-la-torrela-comintern-y-el-peru-acercamientos-y-desencuentros.

- (2001), Stanislav Pestkousky (el compañero Andrés). Un doble retrato en el interior de México [en ruso], San Petersburgo: CLEIO.

- (1999), “¿Quien diablos era Andréi? Stanislav Pestkovski. Camarada Andréi. Una tentativa de una investigación histórica", Memoria. Boletín de CEMOS, $\mathrm{n}^{\circ} 3$.

Jeifets, V. y J. Irving Reynoso (2014), "De frente único a clase contra clase: comunistas y agraristas en México posrevolucionario", Izquierdas, $\mathrm{n}^{\circ}$ 19, pp. 15-40.

Kurella, A. (1930), Ot Berlina do Moskvy, Moscú: Molodaya Gvardiya.

Martínez Verdugo, A. (ed.) (1985), El comunismo en México, México: Grijalbo.

Melgar Bao, R. (1992), "Memoria Roja de los años veinte. Testimonio de Rafael Carrillo", Memoria. Boletín de CEMOS, n 92.

Ortiz, R. (2011), "Komintern i konflikty v Meksikanskoi kommunisticheskoi partii, 1925-1926 gg.", Latinoamerikanskii istoricheskii almanakh, n 11 .

Pakkasvirta, J. (1997), ¿Un continente, una nación?, Helsinki.

Shipman, C., It Had to Be a Revolution, Ithaca-London: Cornell University Press.

Skalov, G.B. (ed.) (1934), Problemy Yuzhnoi i Karaibskoi Ameriki, Moscú: IMHiMP.

Spenser, D. (1998), El triángulo imposible, México: Porrúa.

Stettlerm, P. (1980), Die Kommunistische Partei der Schweiz: 1921-1931, ein Beitrag zur schweizerischen Parteiforschung und zur Geschichte der 
schweizerischen Arbeiterbewegung im Rahmen der Kommunistischen Internationale, Berna: Francke.

Studer, B. (1994), Un parti sous influence: Le parti communiste suisse, une section du Komintern, 1931 a 1939, Lausana: L'Age d'Homme.

Taibo II, P.I. (1986), Los Bolshevikis, México: J.P. Mortiz.

Titulo: "The relationship between the Comintern and Latin America: episodes of the Swiss revolutionary Alfred Stirner".

Resumen: En el presente articulo los autores investigan varios historias poco conocidas de la activad del comunista suizo Edgar Woog ("Alfred Stirner" (18981973), sobre todo el papel desempeñado por este funcionario cominternista en el desarrollo de relaciones de la III Internacional con el revolucionario peruano Víctor Raúl Haya de la Torre y el Partido Revolucionario Venezolano, asi como con el PCM durante el período de la formación y declive del alianza entre comunistas y el movimento campesino independiente. Al analizar estos epidodios, indican el carácter cambiante y "creative" de relaciones entre la III Internacional y sus secciones naciones latinoamericanas. Además, los autores prestan atención a la evolución de los punta de vista del revolucionario suizo acerca de los procesos sociopolíticos dentro de la izquierda latinoamericana.

Palabras clave: Edgar Woog, Comintern, Haya de la Torre, Partido Revolucionario Venezolano, Liga Nacional Campesina

\begin{abstract}
The authors are analyzing some little-known episodes of the activity of the Swiss Communist Edgar Woog ("Alfred Stirner" (1898-1973), especially the role of this Comintern's official in the development of the relations between the III International, the Peruvian revolutionary Víctor Raúl Haya de la Torre and the Partido Revolucionario Venezolano, as also with the Mexican Communist Party within the period of formation and decline of the alliance between the communists and the independent peasants' movement. The authors show the changing and "creative" character of the relationship between the Comintern and its national sections in Latin America. Additionally, the authors make some research of the evolution of Stirner's points of view over the social and political processes within the Latin American Left-Wing movement.
\end{abstract}

